\title{
Zero Net Energy Consuming Residential Houses
}

\author{
Z. Melikyan and S. Egnatosyan \\ Department of Heating, Ventilation and Air Conditioning, National University of Architecture and Construction of Armenia, Yerevan, \\ 0009 Armenia
}

\begin{abstract}
Preliminary investigation of the assigned task shows that the energy efficiency of residential houses is conditioned by the quantity of energy, consumed by all internal energy providing systems that serve for creation of comfort microclimate in all rooms of the building. The energy consuming systems of residential houses are: heating, ventilation, air conditioning, domestic hot water providing, tap water supplying systems and other life supporting facilities. If the listed systems consume possibly least quantity of energy or so cold zero net energy, the building can be qualified as energy efficient. The authors of this article try to give right answers how to provide the best, cheapest and ecologically safe solutions of assigned tasks. One of the radical solutions of the problem is the development and use of fossil fuel non-consuming installations of energy production. To overcome of mentioned problems the authors developed new type of thermal and electrical energy generating high efficiency local and central systems. For this reason, the authors of this study decided to develop new generation of heating, ventilation and domestic hot water supplying high efficiency integrated systems.
\end{abstract}

Key words: Heating system, fossil fuel non-consuming local heating system, natural ventilation, domestic hot water provision refrigerant gas, energy consumption, energy saving.

\section{Introduction}

Increase of energy efficiency of residential houses can be achieved by increasing efficiency of all energy consuming facilities of houses. The energy most consuming systems of houses are the heating systems. The methods for ensuring of energy efficient heating technologies are suggested in Refs. [1,2].

Energy efficient ventilation of residential houses is one of dominating problems. Traditionally the natural ventilation was in large use because of its simplicity and low consumption of energy. After relatively short period of mechanical ventilation's excessive use the interest to natural ventilation again increased because of energy supplying problems and deficit of electricity.

However, in spite of many advantages these electric stations are characterized by disadvantages, which drastically decrease their effectiveness and create serious social and economic problems. The amount and nature of emissions depend on type of consumed fuel.

Corresponding author: Zohrab Melikyan, Doctor, professor, research field: energy.
For avoiding of raised problems and simplifying structures of electricity generating stations it is suggested to develop electricity generating stations consisting of energy producing separate small equipment that can be used for assembling electricity generating technologies. Nevertheless, in all cases the energy efficiency and cost effectiveness stay the main requirements for adopting of developed systems into relying. From this point of view, the simplicity of structure and effectiveness of energy generating new technology, based on assemblage of energy generation stations assembled from energy producing separate small equipment is the question of critical importance. As such, equipment can serve well-known reciprocated and turbo compressors, turbo expanders, electricity generators and various auxiliary equipments that are in production almost in all countries [3-5].

\section{Methods for Increasing of Energy Efficiency of Natural Ventilation}

The insufficient operation of a natural ventilation system takes place in two cases: first when it does not provide normative quantity of air in each of rooms of 
a building, second when exhaust grills operate like plenum, which creates reverse flow of outside air into the rooms. In wintertime, because of outside air's low temperature the air exchange can exceed the normative rate. On the other hand, insufficient air change is very dangerous for health especially for the children. Deficit of fresh air in houses causes increase of relative humidity, which damages structures of buildings. The main reason of bad ventilation takes place because of absence of the balance between exhaust and plenum airs. Breach of air balance does not allow the fresh air to enter into rooms of a building. For multistory houses efficiency of natural ventilation for various floors are different. As a rule, the critical situation takes place in last two stories. However, some methods like thermal impulse can help for intensifying of natural ventilation.

\section{Method of Thermal Impulse for Intensification of Natural Ventilation}

This method is accomplished by heating of the exhaust air's ducts. For intensifying the air exchange in rooms, it is quiet enough to heat the air of exhausting air ducts up to $5{ }^{\circ} \mathrm{C}$ higher, than external air. To heat the air ducts without big consumption of heat can be used waste heat sources in forms of warm flue gases, evacuated from gas stoves or warm humid air of shower. In wintertime, the surplus ventilation brings to unjustified increases of energy, consumed for heating of the house. Driving force of the natural ventilation process is the gravitation pressure, which is proportional to the difference of internal and external densities of air and as well of height of exhausting warm duct. The calculation of natural ventilation and selection of diameters of ducts are executed in accordance to acting norms for external air $5{ }^{\circ} \mathrm{C}$ and for internal air $20{ }^{\circ} \mathrm{C}$. Just under these temperatures, the air exchange corresponds to sanitary norms. For multistory houses the efficiency of natural ventilation for different stories of the houses is different. As a rule, the situation becomes critical in last two stories.

\section{Wind Impulse for Intensification of Natural Ventilation}

The wind impulse is the use of wind's kinetic energy for ejection of ventilation used air from ducts by the help of deflectors. Principle of operation of a deflector is based founded on the effect of Bernoulli that declares: "lower the diameter of the pipe, higher the velocity of the liquid's stream in narrow cross sections of pipes, and higher the velocity of the flow in a pipe lower the static pressure". At present, the interest towards deflectors grows because of absence of energy consumption and rather efficient operation as natural ventilation facilities for different types of buildings.

\section{Developing of Electricity Generating Station, Assembled from Energy Producing Separate Small Equipment}

Fig. 1 shows one of possible schemes of an electricity generating station, assembled from separate equipment.

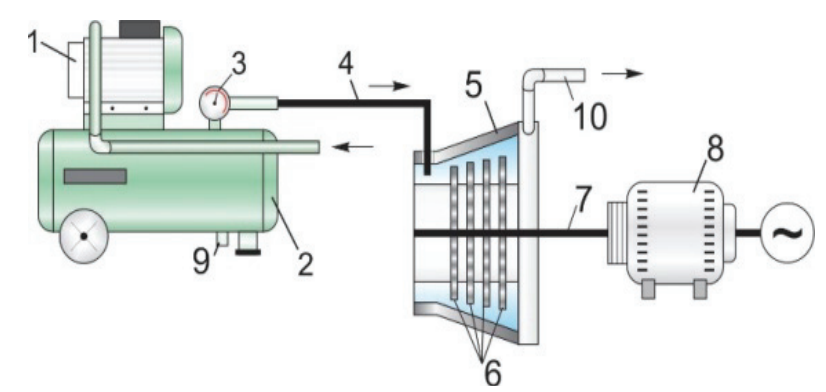

Fig. 1 Principal scheme of suggested electricity generating new station.

1-air compressor with electric starter; 2-receiver of compressed air; 3-air pressure regulating gauge; 4-compresed air turbo expander's feeding pipeline; 5-turbo expander of air; 6-reactive blades of air turbo expander; 7-electricity generator's rotor driving shaft; 8 -electricity generator; 9-condensate periodically removing automatic valve; 10 - outlet of low pressure used air. 


\section{Operation of Energy Generating New Station, Functioning by Novel Technology}

According to the suggested novel technology, the electrical energy generating station operates in the following way: the air compressor (1) compresses outside or inside air up to pressure $P_{\text {exp.in }}$ and forces into the receiver (2) of compressed air. The volume of the receiver (2) depends on designed working regime of the station that conforms to the regime of generated electricity consumption, which in its turn depends on diagrams of energy consumers. The regulator (3) automatically controls the pressure of air in the receiver (2). The compressed air by the high-pressure air's inlet tube (4) from the receiver (2) of compressed air is forced into the turbo expander (5) where it expands adiabatically up to the atmospheric pressure. Because of air expansion, the reactive blades (6) of turbo expander are rotating and spinning the shaft (7) of electric generator (8). Because of rotation, the electric generator (8) produces electricity, the specific quantity $l,(\mathrm{~kJ} / \mathrm{kg})$ of which is determined by the following equation [6-8]:

$$
l=\frac{Z R T_{\text {exp. in }}}{k-1}\left(1-\left(\frac{P_{\text {exp.out }}}{P_{\text {exp.in }}}\right)^{\frac{k-1}{k}}\right)
$$

where, $Z=1.04$ compressibility factor of air [9], $R=$ $287 \mathrm{~J} /\left(\mathrm{kg}^{\circ} \mathrm{C}\right)$ - gas constant of air $[10,11]$, $T_{\text {exp.in }}$-initial temperature of air at the inlet of turbo-expander, $P_{\text {exp.in }}$-initial pressure of the atmospheric air at the inlet of turbo-expander, $P_{\text {exp.out }}=$ 1 bar-pressure of the air at the outlet of the turbo-expander, $k=1.4$-adiabatic or isentropic exponent for air [10].

Temperature of air at the inlet of turbo-expander $T_{\text {exp.in }}$, can be determined by the following equation [7-9]:

$$
T_{\text {exp.in }}=T_{\text {air.out }}\left(\frac{P_{\text {atm }}}{P_{\text {exp.in }}}\right)^{\frac{1-k}{k}}
$$

where, $T_{\text {air.out }}$ outside air temperature, is adopted (for summer time: $308{ }^{\circ} \mathrm{K}$, and for winter time: $254{ }^{\circ} \mathrm{K}$ [12]), $P_{\text {atm }}=1$ bar-pressure of atmospheric air.

The results of calculations, made by Eqs. (1) and (2) are shown in Fig. 2 in form of diagrams.

As shown in Fig. 2, because of higher temperatures of air at the inlet of the turbo-expander the quantities of produced specific energy, in summertime in $17 \%$ are higher, than in wintertime. That is to say, the efficiency of turbo expander in summertime is higher, than in wintertime. Taking into account that whole the air of the receiver in quantity $G_{\text {air }}(\mathrm{kg} / \mathrm{s})$, is expanded in turbo-expander, the absolute value of electric power $N_{\text {exp }}$ produced by the turbo expander will make the values represented by the diagram of Fig. 3.

The power, developed by turbo expander is determined by the following equation:

$$
N_{\text {exp }}=G_{\text {air }} l
$$

where, $G_{a i r}$-quantity of air, expanded in the turbo expander $(\mathrm{kg} / \mathrm{s})$.

Fig. 3 shows that power, produced by turbo expander depends on air quantity $G_{\text {air }}(\mathrm{kg} / \mathrm{s})$, is supplied into the turbo expander. For example, capacity of the receiver, which is prescribed for screw type compressor ABT $500 / 2,000$ of "Fiak" company, is $500 \mathrm{~L}$, and the air productivity of the compressor is $2,000 \mathrm{~L} / \mathrm{min}$ or 0.04 $\mathrm{kg} / \mathrm{s}$ with pressure $10 \mathrm{bar}$ [13] develops power $N_{\text {exp }}$ the value of which, according to Eq. (3), makes: $N_{\text {exp }}=0.04 \cdot 214=8.56 \mathrm{~kW}$.

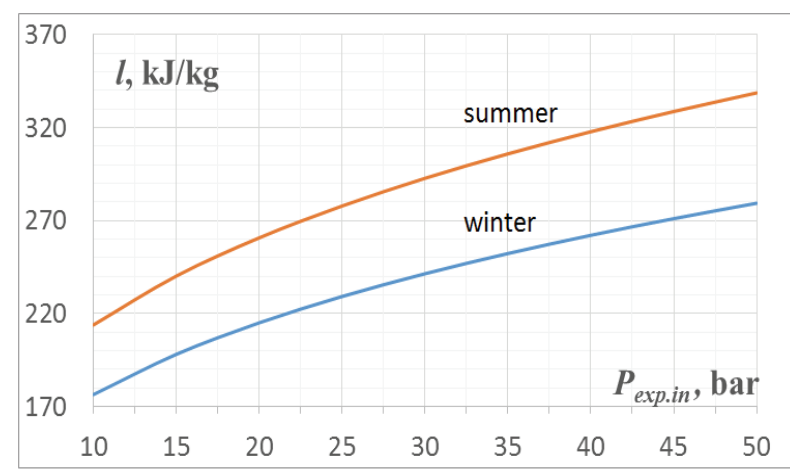

Fig. 2 Diagram of values of specific energy $l(\mathrm{~kJ} / \mathrm{kg})$ produced in summer and winter periods, depending on pressure of air $\boldsymbol{P}_{\text {exp.in }}$ at the inlet of air expander. 


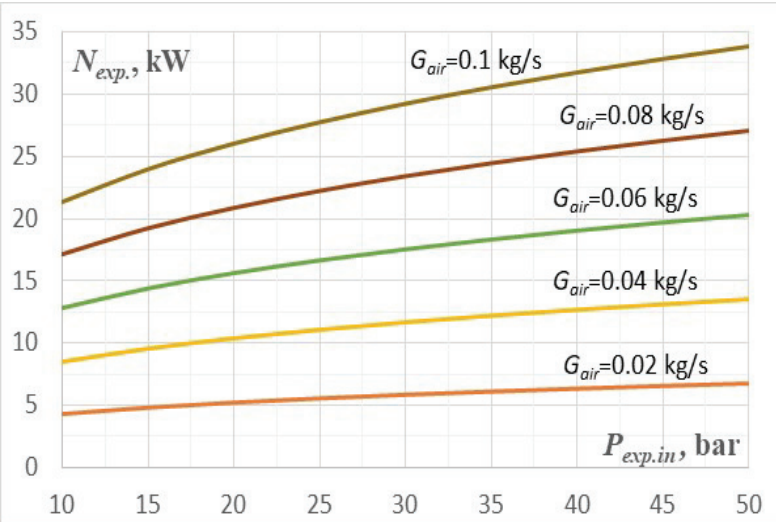

Fig. 3 Power developed by turbo expander depending on quantity of expanded air.

\section{Design of Electricity Station on Example of a Low Rise Residential House}

The order of design of electricity station for a house or for other electricity consumer is the following:

(1) Determination of electricity demand of the consumers;

(2) Developing of electricity supplying and distributing scheme by all consumers;

(3) Determination of characteristics of electricity producing separate small equipment and their selection;

(4) Determination of energy-economic characteristics of designed electricity station.

An example of electric station designed for a 4-story residential house is shown in Fig. 4.

Automated receiver of compressed air controls the regime of operation of energy producing main small equipment like compressor, and high-pressure air turbo expander in the following way: a day is divided in three intervals of time with 8 hours duration each. During each interval, a process is executed. So in first 8 hours interval the compressor operates and fills up the receiver with compressed up to 10 bar air, afterwards the compressor automatically stops operating and second 8 hours interval starts, during of which through open automatic valve the high-pressure air expands and through air turbo expander paces from the receiver into atmospheric air and during second 8 hours electricity generation takes place.

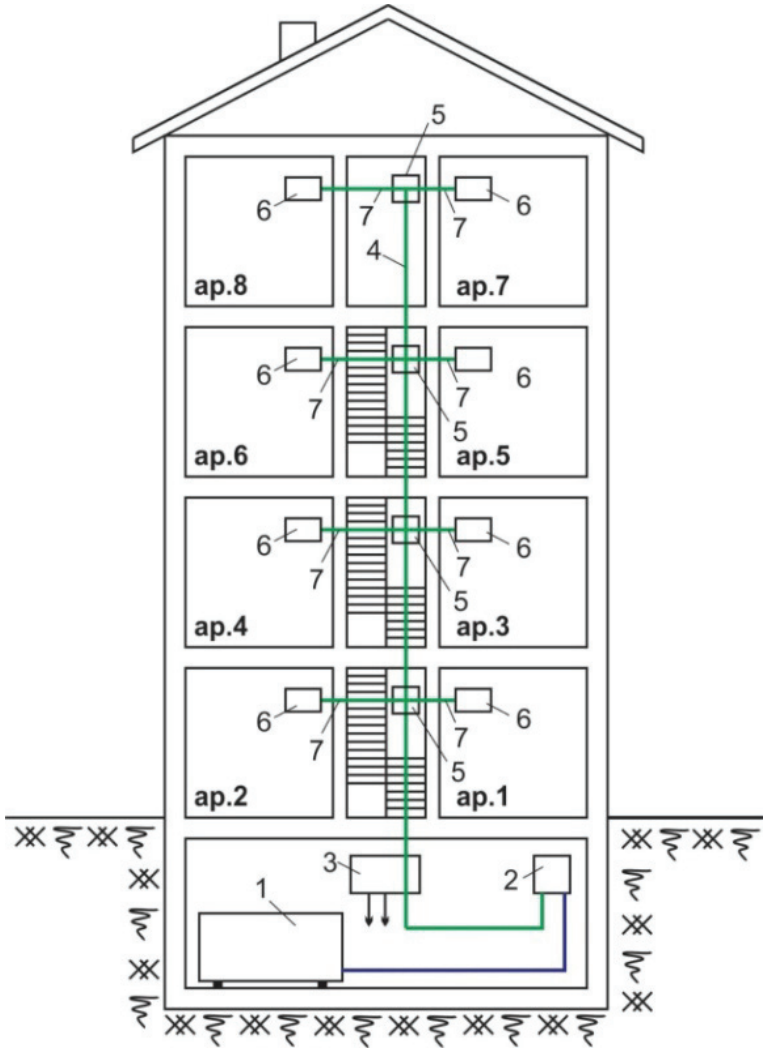

Fig. 4 Scheme of 4 story residential house with electricity generating new station and electricity supplying network. 1 - electricity generating new station with transformer of the electric station, installed in the basement of 4 story residential house; 2-electricity main meter of the house; 3-main distributor of electricity; 4 -electricity distributing main cord; 5-electricity distributors by stories (floors); 6-electricity meters by apartments; 7-distribution cords.

Taking into consideration above explanations Eq. (1) can be transformed into the following one:

$$
l=\frac{\tau \cdot Z R T_{\text {exp.in }}}{k-1}\left(1-\left(\frac{P_{\text {exp.out }}}{P_{\text {exp.in }}}\right)^{\frac{k-1}{k}}\right)
$$

where, $\tau=8$ hours or $\tau=28,800 \mathrm{~s}$-duration of interval of time when the station generates energy.

The power of electric station $N_{s t}$ of the considered building is determined by the following equation:

$$
N_{s t}=\frac{n_{a p} \cdot q_{e l . d e m}}{H}
$$

where, $n_{a p}=8$-number of apartments of the building, $q_{\text {el.dem. }}$ - electricity demands by each apartment per month, $\mathrm{H}=720$ hours - duration of a month in hours. 


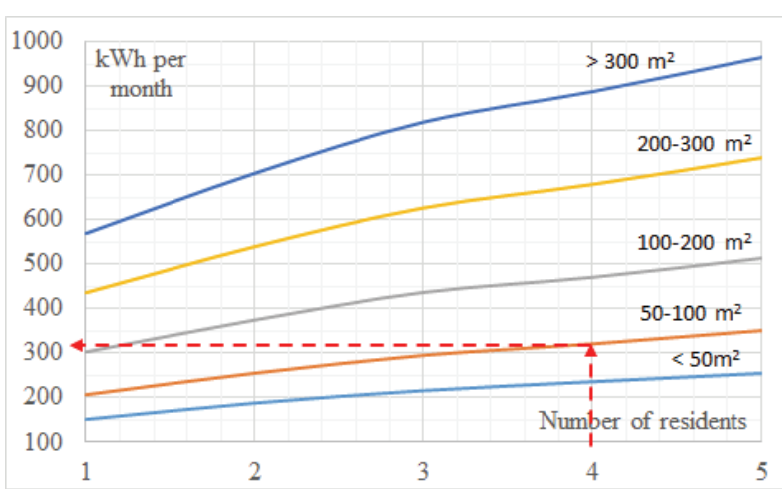

Fig. 5 Normative consumption of electric energy in residential houses depending on number of residents and surfaces of apartments [14].

According to diagram of Fig. 5, the electricity demands of apartments with 4 residents each and 100 $\mathrm{m}^{2}$ of surface makes $q_{\text {el.dem. }}=320 \mathrm{kWh} /$ month.

Substitute of above data in Eq. (5) and making calculations, will determine the following power, generated by the designed electric station: $N_{s t}=3.56$ $\mathrm{kW}$.

\section{Tariff of Electricity, Generated by Developed New Station}

The tariff of energy is the average cost of $1 \mathrm{kWh}$ of energy, generated by electric station.

The tariff of generated electricity is determined by the following equation:

$$
T_{f}=\frac{\frac{\Sigma K}{Y}+\Sigma U}{\Sigma l}
$$

where, $\Sigma K$-total capital cost (\$), of the assembled power plant, $\Sigma U$-annual operational cost of the power plant (\$/year), $Y$-capital investment's payback period, which is selected to be equal to the life cycle duration of the station or any other period in case of which the cost of electricity supply $\mathrm{T}(\$)$ becomes affordable for consumers and acceptable for investors, year, $\Sigma l$-quantity of energy ( $\mathrm{kWh} /$ year), generated by electric station during one year.

The total capital $\operatorname{cost} \Sigma K$ of the assembled power plant, is the sum of energy producing separate small equipment that is determined by the following expression:

$$
\Sigma K=\left(K_{\text {comp }}+K_{\text {tur. } \text { exp }}+K_{\text {el.gen }}\right) \cdot 1.4
$$

where, $K_{\text {comp }}$ - cost of compressor with receiver (\$), $K_{\text {tur.exp }}$ - cost of turbo expander (\$), $K_{\text {el.gen }}$ - cost of electricity generator (\$), 1.4 -electric station's assembling and testing labor cost and in addition, extra expenditures factor.

8.1 Cost of Compressor and Receiver Are Defined by the Following Production

$$
K_{\text {comp }}=C_{\text {comp }} G_{\text {air.comp }}
$$

where, $C_{\text {comp }}=2.92 \$ /($ litre $/ \mathrm{min})$ specific cost of

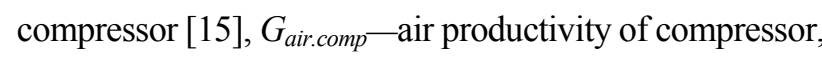
depending on the quantity of air passing through the air expander. The air productivity of the compressor can be determined by the following production:

$$
G_{\text {air.comp }}=\frac{N_{\exp } 1000 \cdot 60}{l_{\text {exp }} \rho_{\text {air }}}=\frac{3.56 \cdot 1000 \cdot 60}{214 \cdot 1.2}=831.78
$$

litre/min

Substitute of values $C_{\text {com }}$ and $G_{\text {air.com }}$ into Eq. (8) will obtain the capital cost of the compressor:

$$
K_{\text {comp }}=2.92 \cdot 831.78=\$ 2429
$$

\subsection{Cost of Turbo Expander Is Defined by the} Following Production

$$
K_{\text {tur.exp }}=C_{\text {exp. }} N_{\text {exp. }}
$$

where, $C_{\text {exp }}$-specific cost of turbo expander which according to Ref. [16] makes from $\$ 600$ to $\$ 2,300$. The average specific cost makes $1,450 \$ / \mathrm{kW}, N_{\text {exp }}$ - power of turbo expander, which according to Eq. (5) for the 8 apartments of 4 story house makes $3.56 \mathrm{~kW}$.

Substitute of values $C_{\text {exp }}$ and $N_{\text {exp }}$ into Eq. (9) and making calculations will obtain the following capital cost of the turbo expander: $K_{\text {tur. } \exp }=1450 \cdot 3.56=\$ 5162$.

\subsection{Cost of Electricity Generator}

Because of absence of mass manufacturing of electric generators, which are similar to the electric 
generator which is invented in this article, the cost of electricity generator used in considered electric station is taken about the same as the cost of electric motor of the same $4 \mathrm{~kW}$ power, which is produced by the company "Energodrive" makes $K_{\text {el.gen }}=\$ 134$ [17].

Substitute costs of all equipment in Eq. (7) will determine the following total capital cost $\Sigma K \$$, of the assembled power plant:

$$
\Sigma K=(2429+5162+134) \cdot 1.4=\$ 10815
$$

Total annual operational cost of considered power plant consists only of current repair cost of new electric station, which does not exceed $4 \%$. For this reason, the current repair cost is neglected.

Quantity of energy, generated by electric station during one year makes:

$$
\Sigma l=\tau_{\text {year }} N_{s t} m_{o p .}=8640 \cdot 3.56 \cdot 0.8=24607 \mathrm{kWh} / \text { year }
$$

where, $\tau_{\text {year }}$-total number of working hours of the station during a year, $m_{o p}=0.8$ - coefficient of yearly operating hours of the station.

Conformably, the tariff of energy, generated by suggested electric station makes:

$$
T_{f}=\frac{10815}{25 \cdot 24607} \approx 0.018 \$ / \mathrm{kWh}
$$

The obtained value of the electricity tariff proves that developed electric station, based on suggested new technology is more efficient compared to existing in Armenia powerful centralized electric stations functioning by Rankin and combined cycles the electricity tariff of which makes $0.08 \$ / \mathrm{kWh}$ which in 4.44 times is lower, than the tariff of electricity, generated by centralized thermal power plants.

\section{Structure and Operation of Fossil Fuels Non-consuming Heating, Ventilation and Domestic Hot Water Providing Integrated System}

As shown in Fig. 6, the developed integrated heat supplying and ventilating system has rather simple structure. The system consists of three main sections,

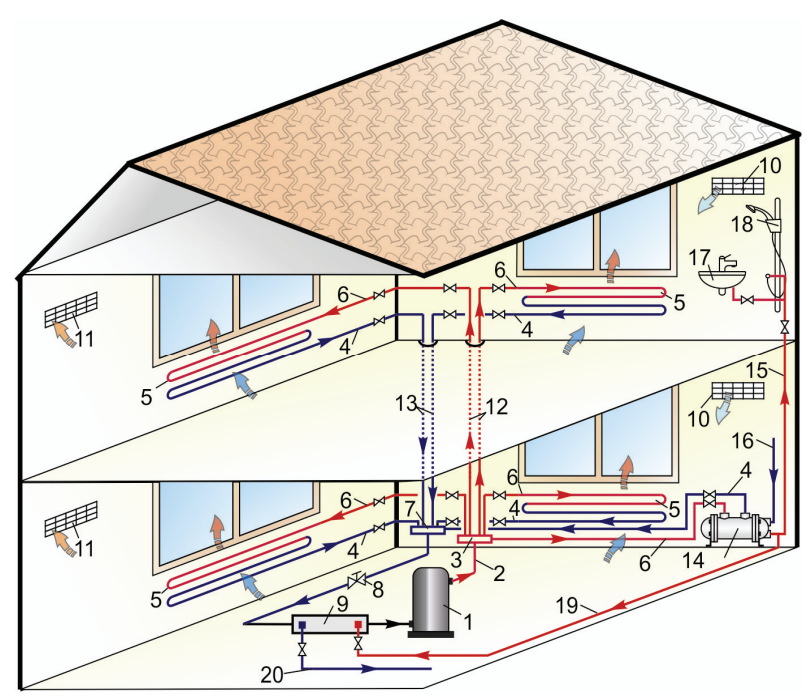

Fig. 6 Fossil fuels non-consuming heating, ventilation and domestic hot water supplying system of a family house.

1-R-22 refrigerant compressor; 2-compressed hot gas supplying pipeline; 3-R-22 hot gas-supplying collector; 4-R-22 condensed gas return pipeline; 5 - pipe type air heater; 6-liquid R-22 return pipeline (branch) to the liquid's collector; 7-liquid R-22 return collector; 8-throttling valve; 9-hot water to liquid R-22 heat exchanger; 10 -ventilation air inlet scapular valve; 11-ventilation air outlet scapular valve; 12-R-22 hot gas supplying stands; 13 -return stands of R-22 liquid refrigerant; 14 -domestic hot water preparation heat exchanger; 15-domestic hot water supplying pipeline; 16-tap water pipe; 17-hand- wash stand; 18 - shower; 19-hot water pipe to heat exchanger (9); 20 - cooled water return pipeline.

which provide all kinds of energy consumptions of a residential house, which are: 1 -heating; 2-ventilation; 3 -domestic hot water preparation and distribution.

Preliminary investigation proves that most suitable and efficient heat carrier for suggested system can serve refrigerant Freon R-22. The compressor (1) is installed in the basement of the house. Freon gas supplying pipelines (2) and distributing collectors (3) are connected to pipe type air heaters (4), which hangs on walls or stand on floors of the rooms.

The suggested heat supplying integrated system operates in the following way: the compressor (1) is installed in the basement of the house and serves for compression of Freon R-22 gas. Because of compression, the R-22 gas is heated and through the hot R-22 supplying stands (2) of heating system is forced into the hot gas supplying collector (3). From 
the hot gas-supplying collector (3) the compressed hot gas is distributed among the pipe type air heaters (5), which are hanged on inside walls, on ceiling or stand on the floors of rooms. Because of heat transfer from hot gas of R-22 to inside air of the house, Freon gas condenses and by liquids' stands (6) returns into the liquid's collector (7).

Afterwards the liquid R-22 passes through throttling (expanding) valve (8) where it decreases its pressure and temperature. Then the cooled liquid passes through the "hot water-liquid R-22" heat exchanger (9) where from hot water absorbs heat. As a result, the liquid refrigerant is evaporated and the compressor (1) sucks the vapor of R-22 for repeating above described processes.

For providing $t_{\text {ins }}=18{ }^{\circ} \mathrm{C}$ [18] inside comfort temperature in winter period, the outside fresh air through air filter and plenum ventilation grills (10) enters into the inside area of the house which contacts the external hot surface of the pipe type air heaters (6). Through tubes of pipe type air heater flows compressed in the compressor (1) hot refrigerant gas. As a result, of heat exchange, the hot refrigerant gas transfers heat to the inside air, which contacts external hot surface of air heater tubes (6). The heated air is extended in the room and heats the inside space. Because of heat exchange with inside air, the compressed refrigerant gas is condensed in pipe type air heater tubes and sequentially passes through throttling valve (8) and then heat exchanger (9), where, by absorbing heat from hot water, the liquid refrigerant is evaporated and the compressor (1) sucks the vapor of R-22 for repeating above described processes. The domestic hot water is prepared in heat exchanger (14) which is installed in basement of the house, and is connected with tap water (16) and domestic hot water (15) supplying pipelines.

\section{Main Equipment's Characteristics of Heat Supplying Integrated System}

The most important feature of suggested system is the absence of the heating boiler, which is replaced by a refrigeration compressor. Consequently, the main equipment of heat supplying integrated system is the followings: $1-\mathrm{R}-22$ gas compressor (1); 2-pipe type air heaters (5); 3- hot water preparing heat exchanger (14); 4-hot water to liquid R-22 heat exchanger (9).

Based on results of calculations accomplished by the method, published in Refs. [19, 20] wintertime heating demands' diagrams of considered family house were composed, which is represented in Fig. 7.

Fig. 7 shows that the specific heating demands, $q_{h d}$ $\left(\mathrm{W} / \mathrm{m}^{3}\right)$ of the considered house with sizes $a=12 \mathrm{~m}, b$ $=12 \mathrm{~m}$ and $h=3 \mathrm{~m}$ (volume is $432 \mathrm{~m}^{3}$ ) makes 25.6 $\mathrm{W} / \mathrm{m}^{3}$.

For finding the absolute value of heating demand, $Q_{h d}(\mathrm{~W})$, the specific value $q_{h d}\left(\mathrm{~W} / \mathrm{m}^{3}\right)$ is multiplied by the volume $V_{b}$, of the building:

$$
Q_{h d}=q_{h d} V_{b}=25.6 \cdot 432=11059 \mathrm{~W} \text { or } 11 \mathrm{~kW}
$$

\section{Determination of Required Total Length of Pipe Type Air Heater Tubes}

For providing inside comfort temperature in the house, the pipe type air heater tubes (6) should have appropriate total $L_{t o t}$ length. To reveal the required value of total length of air heater tubes, the following equation of heat transfer $[21,22]$ is applied:

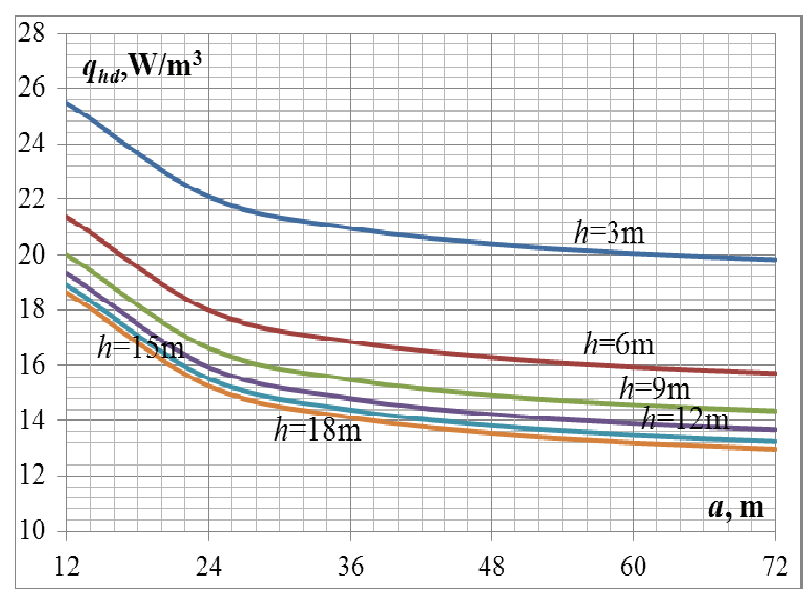

Fig. 7 Values of specific heating demands $q_{h d}\left(W / m^{3}\right)$ of the house at outside design temperature $t_{\text {out.dsg }}=-19{ }^{\circ} \mathrm{C}$, and required inside temperature $t_{i n}=18{ }^{\circ} \mathrm{C}$, depending on sizes of buildings (lengths $a=12 \mathrm{~m}$ to $72 \mathrm{~m}$, heights $h=3$ to $18 \mathrm{~m}$ and widths $b=12 \mathrm{~m}$ ). 


$$
Q_{h d}=\pi d_{\text {ext }} L_{t o t} \alpha_{e x t}\left(t_{\text {liq. R22 }}-t_{\text {ins. }}\right)
$$

where, $Q_{h d}$-heating demand of the house, which conditions the total heat productivity of pipe type air heater tubes; $d_{e x t}=0.01 \mathrm{~m}$-external diameters of air heater tubes; $L_{t o t}$ - - total length of air heater tubes, $\alpha_{\text {ext }}=$ $100 \mathrm{~W} /\left(\mathrm{m}^{20} \mathrm{C}\right) \quad[23]-$ convective heat transfer coefficient on external surfaces of air heater tubes, $t_{\text {liq.R22 }}=45{ }^{\circ} \mathrm{C}$-temperature of condensed $\mathrm{R}-22$ refrigerant gas, in air heater tubes, $t_{\text {ins }}=18{ }^{\circ} \mathrm{C}$-design temperature of inside air of the house.

For finding the total length of air heater tubes, Eq. (11) is converted into the following fraction:

$$
L_{\text {total }}=\frac{Q_{h d}}{\pi d_{\text {ext }} \alpha_{\text {ext }}\left(t_{\text {liq.R22 }}-t_{\text {ins. }}\right)}
$$

Substitute of given above characteristic values in Eq. (12) and making calculations will derive the following required total length of air heater tubes to cover 11,000 $\mathrm{W}$ of heating demand of the house:

$$
L_{\text {total }}=11000 /(3.14 \cdot 0.01 \cdot 100 \cdot(45-18)) \approx 130 \mathrm{~m}
$$

From $130 \mathrm{~m}$ long copper tub with diameter $d_{e x t}=$ $0.01 \mathrm{~m}$ can be made coiled radiators for using them as heating appliances of rooms. Fig. 8 shows developed "Pipe type" heating appliance of the building.

For heating purposes, high temperature heat carrier should circulate through air heater tubes. In the considered system, the hot liquid of Freon R22 can serve as heat carrier. Hot liquid Freon's preparation processes are represented on enthalpy-pressure (i- $\log \mathrm{P})$ diagram of R-22 refrigerant [24, 25].

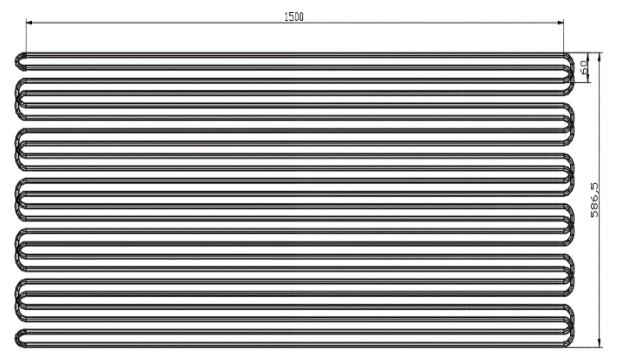

Fig. 8 "Pipe type air heater" heating appliance of the building.

\section{Determination of Energy Consumption by the Heat Supplying Integrated System}

The consumers of energy in the suggested heating, ventilating and domestic hot water providing integrated system are the compressor (1), domestic hot water providing system, hot water preparing heat exchanger (14) and hot water to liquid R-22 heat exchanger (9). To define compressor's energy consumption, on the diagram (i- $\log \mathrm{P}$ ) of R-22 gas compression and other related processes are plotted. Fig. 9 represents (i- $\log \mathrm{P})$ diagram of R-22 with related processes taking place during operation of suggested integrated system.

In Table 1 the values of enthalpies, pressures and temperatures of characteristic points of R-22 gas compression cycle are represented.

Refrigerant's flow rate Gag, in the system is:

$$
G_{a g}=Q_{h d} /\left(i_{2}-i_{3}\right)=11 \mathrm{~kW} /(451-248)=0.054 \mathrm{~kg} / \mathrm{s} \text {. }
$$

Power, consumptions by processes, represented in Fig. 9 are the followings:

- process «1-2»-compression of the gas refrigerant in the compressor- $N_{1-2}=G_{\mathrm{ag}}\left(i_{2}-i_{1}\right)=$ 0.054. $(451-417)=1.85 \mathrm{~kW}$;

- process «2-3»-R-22 refrigerant's condensation in air heating tubs and rejection of condensation heat into the inside space of the house

$$
Q_{2-3}=G_{a g}\left(i_{2}-i_{3}\right)=0.054(451-248)=11 \mathrm{~kW}
$$

- process «4-1»-R-22 liquid refrigerant's evaporation of liquid R-22 "in hot water to liquid R-22" heat exchanger: $Q_{4-1}=G_{a g}\left(i_{1}-i_{4}\right)=0.054(417-248)=$ $9.1 \mathrm{~kW}$.

From the last expression it is clear that for evaporation of liquid refrigerant in the heat exchanger (9), $Q=9.1 \mathrm{~kW}$ of heat should be transferred from hot water to liquid R-22.

$$
G_{w}=\frac{Q_{4-1}}{c_{w}\left(t_{w . i n}-t_{w . \text { fin }}\right)}
$$

where, $c_{w}=4.18 \mathrm{~kJ} /\left(\mathrm{kg}^{\circ} \mathrm{C}\right)$ specific heat of water, $\left(t_{\text {w.in }}-t_{\text {w.fin }}\right)=20{ }^{\circ} \mathrm{C}$-water temperature drop in "hot water-liquid R-22" heat exchanger. 


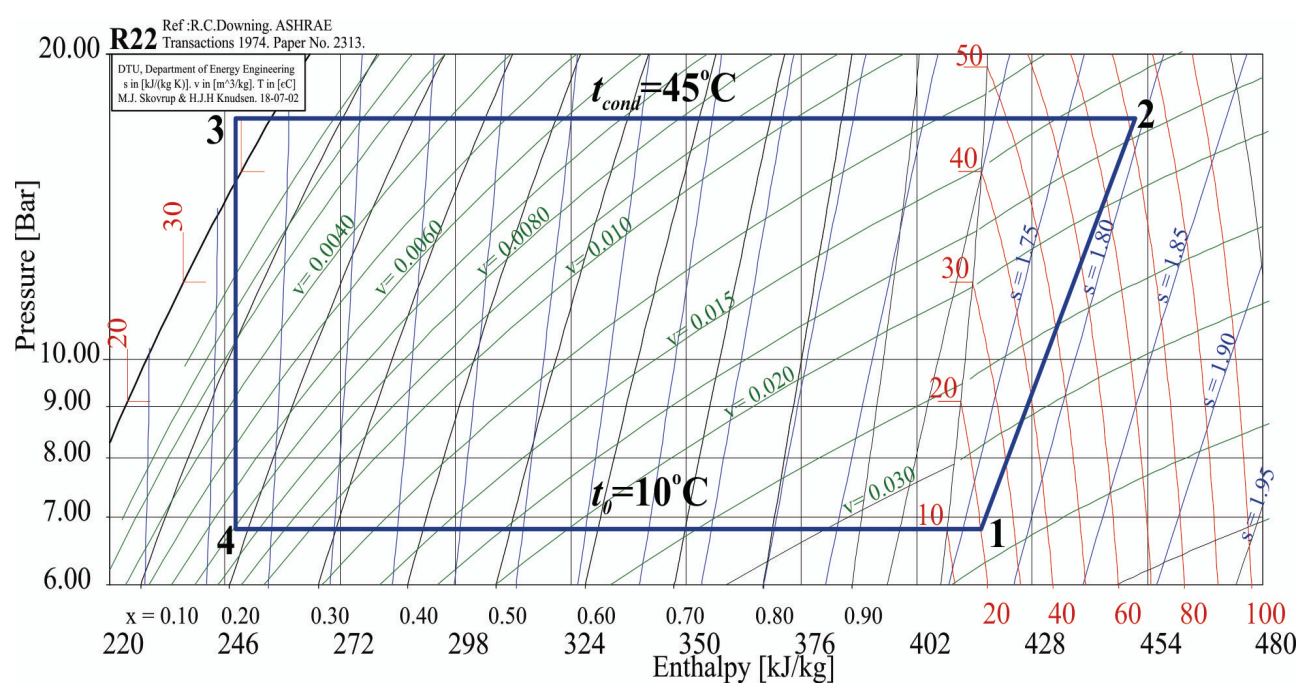

Fig. 9 R- 22 refrigerant's gas compression and other related processes plotted on (i-logP) diagram.

Table 1 Refrigerant's characteristic parameters.

\begin{tabular}{lllll}
\hline Characteristic parameters & Point 1 & Point 2 & Point 3 & Point 4 \\
\hline Pressure (bar) & 6.8 & 17.3 & 17.3 & 6.8 \\
Temperature $\left({ }^{\circ} \mathrm{C}\right)$ & 20 & 83 & 39 & 10 \\
Enthalpy $(\mathrm{kJ} / \mathrm{kg})$ & 417 & 451 & 248 & 248 \\
\hline
\end{tabular}

Substituting in Eq. (5) given above values and making calculations will receive $G_{w}=0.11 \mathrm{~kg} / \mathrm{s}$ of hot water to be supplied into "hot water-liquid R-22" heat exchanger (9).

\section{Energy Efficiency and Cost Effectiveness of Integrated System}

To reveal energy efficiency and cost effectiveness of the developed "integrated" system, it is necessary to compose its optimization mathematical model. The mathematical model represents a set of totality of all equations forming the methods for determination of design, constructive, energy and economic parameters of the system, which are included into the economical functional of the system. The economical functional is the criteria of energy efficiency and cost effectiveness of the system. For determining the value of economical functional $T_{s}\left(\$ / \mathrm{m}^{2}\right.$ year $)$, the following ratio is used [19]:

$$
T_{s}=T / S
$$

where, $T$-seasonal total expenditures made for assembling and operating of "integrated" system (\$/year), $\mathrm{S}=144 \mathrm{~m}^{2}$ - surface of floor of considered house $\left(\mathrm{m}^{2}\right)$.

The required seasonal total expenditures $T$ ( $\$$ year) needed for running of "integrated" system is determined by the following formula:

$$
T=\Sigma K / Y+\Sigma U
$$

where, $\sum K$-total capital cost of the system, (\$), $\sum U$-total seasonal operational cost of the system, $\$$ year, $Y$ - capital investments payback period, which is selected to be equal to the life cycle duration of the system or any other period in case of which the cost of heat supply $T s, \$ /\left(\mathrm{m}^{2}\right.$ year $)$ becomes affordable for consumers and acceptable for investors.

The total capital cost is a function of constructive and energy characteristics of main equipment. For the "integrated" system total capital cost $\Sigma K$ is determined by the following sum:

$$
\Sigma K=\left(K_{\text {comp }}+K_{P . T . A . H}+K_{\text {HEX.d.h.w. }}+K_{\text {evap }}\right) \cdot 1.4
$$

where, $K_{\text {comp }}$ - cost of compressor (\$), $K_{\text {HEX.d.h.w }}-\operatorname{cost}$ of domestic hot water preparing heat exchanger, $\$$, 
$K_{\text {P.T.A.H. }}-$ cost of pipe type air heater (\$), $K_{\text {evap }}-\operatorname{cost}$ of "hot water-liquid R-22" heat exchanger (\$), 1.4-system's assembling, testing and extra expenditures factor.

The costs of listed equipment are determined below. Cost of compressor depends on its cooling capacity and is defined by the following production:

$$
K_{\text {comp }}=C_{\text {comp }} Q_{\text {comp }}
$$

where, $C_{\text {comp }}$-specific cost of compressor $(\$ / \mathrm{kW})$, $Q_{\text {comp }}$ - cooling capacity of compressor (kW).

To determine the specific cost of the compressor special investigation has been accomplished on the example of Danfoss company production [26], aiming at establishing the mathematical function $C_{\text {comp }}=$ $f\left(Q_{\text {comp }}\right)$ on the base of price list of different power consuming compressors. The results of mentioned investigations are represented in form of diagrams, given in Fig. 10.

From Fig. 10 it can be seen that the specific cost for a compressor of $9.1 \mathrm{~kW}$ cooling capacity makes 135 $\$ / \mathrm{kW}$. According to this value, the capital cost of compressor makes: $K_{\text {comp }}=135 \cdot 9.1=\$ 1228$.

Cost of domestic hot water preparing heat exchanger is determined by the following production:

$$
K_{H E X . d . h . w}=C_{H E X} F_{H E X . d . h . w}=20 \cdot 0.25=\$ 5
$$

where, $C_{H E X}=20 \$ / \mathrm{m}^{2}$-the specific cost of "R-22 liquid-water" heat exchanger, $F_{\text {HEX.d.h.w }}$ "R-22 liquid-water" type heat exchange surface, which is determined by the following ratio:

$$
F_{H E X . d . h . w}=\frac{Q_{h . w}}{k_{H E X} \Delta t}=\frac{1000}{350 \cdot 11.5}=0.25 \mathrm{~m}^{2}
$$

where, $Q_{h w}=1 \mathrm{~kW}$-quantity of heat for heating of domestic hot water for 6 person, $k_{H E}=350$ $\mathrm{W} / \mathrm{m}^{20} \mathrm{C}$ - heat transfer coefficient of " $\mathrm{R}-22$ liquid to water" type heat exchanger, $\Delta t$-mean logarithmic temperature difference in counter flow heat exchanger, which is determined by the following equation:

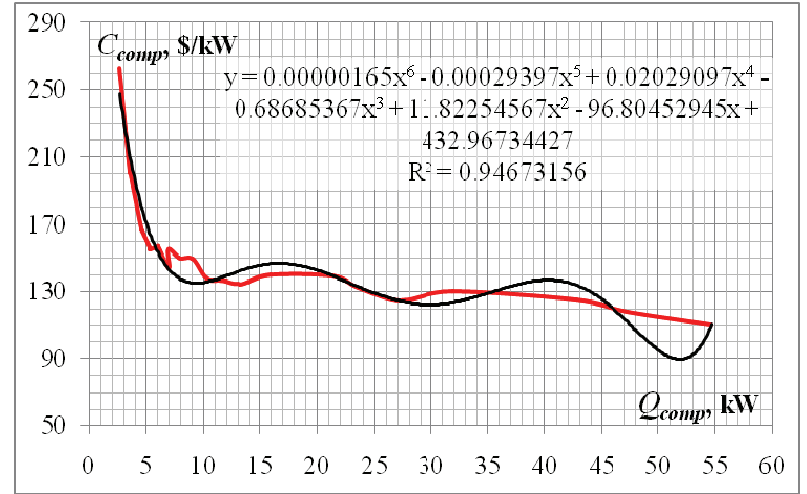

Fig. 10 Specific costs of refrigeration compressor $C_{\text {comp }}$, $\$ / \mathbf{k W}$ of various cooling capacity $Q_{\text {comp }}$, $\mathrm{kW}$ for MTZ type compressors of "Danfoss" company production.

$\Delta t=\frac{\left(t_{\text {cond }}-t_{w 1}\right)-\left(t_{\text {cond }}-t_{w 2}\right)}{\ln \frac{t_{\text {cond }}-t_{\text {w1 }}}{\left(t_{\text {cond }}-t_{w 2}\right)}}=\frac{(45-10)-(45-43)}{\ln \frac{45-10}{(45-43)}}=11.5{ }^{\circ} \mathrm{C}$

where, $t_{\text {cond }}=45{ }^{\circ} \mathrm{C}$-condensation temperature of refrigerant gas in pipe type air heater, $t_{w l}=10{ }^{\circ} \mathrm{C}-$ tap water initial temperature, $t_{w 2}=43{ }^{\circ} \mathrm{C}$-domestic hot water required final temperature.

Cost of "hot water-liquid R-22" heat exchanger is determined by the following production:

$$
K_{\text {evap }}=C_{H E X} F_{\text {evap }}=20 \cdot 1.24=\$ 25
$$

where, $F_{\text {evap }}$-"hot water-liquid R-22" type heat exchange surface, which is determined by the following ratio:

$$
F_{\text {evap }}=\frac{Q_{4-1}}{k_{H E X} \Delta t}=\frac{9100}{350 \cdot 21}=1.24 \mathrm{~m}^{2}
$$

where, $Q_{\text {evap }}=9.1 \mathrm{~kW}$-quantity of heat for evaporation of R-22 liquid refrigerant, $\Delta t-$ mean logarithmic temperature difference in counter flow "hot water-liquid R-22" heat exchanger, which is determined by the following equation:

$$
\Delta t=\frac{\left(t_{\text {w.in }}-t_{0}\right)-\left(t_{\text {w.fin }}-t_{0}\right)}{\ln \frac{\left(t_{\text {w.in }}-t_{0}\right)}{\left(t_{\text {w.fin }}-t_{0}\right)}}=\frac{(43-10)-(23-10)}{\ln \frac{(43-10)}{(23-10)}}=21{ }^{\circ} \mathrm{C}
$$

Cost of pipe type air heater

$$
K_{P . T . A . H}=C_{\text {copper }} L_{\text {total }}=5 \cdot 130=\$ 650
$$

where, $C_{\text {copper }}=5 \$ / \mathrm{m}$-specific cost of $1 \mathrm{~m}$ copper 
tube with diameter $d_{\text {ext }}=10 \mathrm{~mm}$ [27], $L_{\text {total }}$-total length of pipe type copper tube air heater $(\mathrm{m})$.

So, the approximate total capital cost $\sum K(\$)$ for the "integrated" system makes:

$$
\Sigma K=(1228+5+25+650) \cdot 1.4 \approx \$ 2672
$$

Total seasonal operational cost of the "integrated" system is formed from following sum:

$$
\Sigma U=U_{\text {comp }}+U_{r e p}
$$

where, $U_{\text {comp }}$ - cost of seasonal consumption of electricity by compressor (\$/seas.), $U_{\text {rep }}$-seasonal cost of current repair of the system (\$/year).

Seasonal cost of electricity, consumed by the compressor

$$
U_{\text {comp }}=C_{e l} N_{\text {comp }} Z_{\text {seas }} m
$$

where, $C_{e l}=0.08 \$ / \mathrm{kWh}$ tariff of electricity in Armenia, $N_{\text {comp }}=1.8 \mathrm{~kW}$ power capacity of compressor, $Z_{\text {seas }}=$ $3,500 \mathrm{~h}$-durations of heating season in Yerevan, $m$-weather averaging factor for winter heating season.

Cost of seasonal consumption of electricity by the compressor makes:

$$
U_{\text {comp }}=0.08 \cdot 1.8 \cdot 3500 \cdot 0.5=\$ 252
$$

Seasonal cost of current repair of integrated system is determined by the following expression [19]:

$$
U_{\text {rep }}=0.04 \Sigma K=0.04 \cdot 2672=107 \$ / \text { year }(26)
$$

Summing obtained data, will find the following seasonal operational cost of the considered integrating system: $\Sigma U=\$ 252+\$ 107=\$ 359$.

Seasonal expenditures for running the "integrated" system makes: $T=\frac{2672}{25}+359=465 \$ /$ year .
Respectively, the cost of seasonal heating, referred to $1 \mathrm{~m}^{2}$ of building makes $3.2 \$ /\left(\mathrm{m}^{2}\right.$ year $)$.

For evaluating efficiency of integrated system it is compared with another kind of effective heating system that uses fossil fuel in form of natural gas. The cost of seasonal quantity of gas, consumed by gas fired boiler of considered heating system is determined by the following equation:

$$
U_{\text {boil }}=C_{\text {fuel }} B_{\text {gas }} Z_{\text {seas }} m
$$

where, $C_{\text {fuel }}$ - cost of unit of fuel (tariff), $\$ / \mathrm{m}^{3}$, $B_{\text {gas }}$-seasonal consumption of fuel by gas boiler.

The value of $B_{\text {gas }}$ is determined by the help of following fraction:

$$
B_{\text {gas }}=\frac{Q_{\text {boil }}}{\eta_{\text {boil }} Q_{\text {gas }}}=\frac{12}{0.85 \cdot 9.3}=1.52 \mathrm{~m}^{3} / \mathrm{h}
$$

where, $\eta_{b}=0.85$ energy efficiency (COP) of boiler, $Q_{\text {gas }}$-fuel combustion heat capacity $9.3 \mathrm{kWh} / \mathrm{m}^{3}$.

Substitute of above values in Eq. (28) and making calculation will obtain the value of gas consumption which makes $B_{\text {gas }}=1.52 \mathrm{~m}^{3} / \mathrm{h}$. Then according to Eq. (27) the seasonal gas consumption for ordinary system makes

$$
U_{\text {boil }}=0.3 \cdot 1.52 \cdot 3500 \cdot 0.5=798 \$ / \text { seas. }
$$

The integrated system allows saving $2,660 \mathrm{~m}^{3}$ fossil fuel during heating season. In Table 2 are shown comparative energy and economic indices of both systems.

Comparison of data of Table 2 shows that specific cost of seasonal heating $T_{s}$ referred to $1 \mathrm{~m}^{2}$ of the building is $6.6 / 3.2=2.06$ times less than for ordinary system.

Table 2 Comparative energy and economic indices of fossil fuel non-consuming integrated system and heating cooling ordinary systems.

\begin{tabular}{lll}
\hline Characteristics & "Integrated" system & Ordinary system \\
\hline Total capital cost, & 2,672 & 2,012 \\
$\sum K x 1,4, \$$ & 359 & 877 \\
Total seasonal operational cost of system $\Sigma U, \$$ year & 465 & 957 \\
Seasonal expenditures for running the system, $T$ & 3.2 & 6.6 \\
\hline Specific cost of seasonal heating referred to $1 \mathrm{~m}^{2}$ of building, $T_{s}$ & \\
\hline
\end{tabular}




\section{Conclusion}

(1) It is the first attempt to develop electricity station, assembled from energy producing small equipment that can become the first-born one in the range of new generation of electricity producing local facilities.

(2) With successful start of use of suggested new technology new era of local, private and cheap electricity stations with very high efficiency and low cost of produced energy will start.

(3) The tariff of electricity, produced by suggested novel technology will be fourfold lower.

(4) The suggested new order of operation of energy producing small equipment can be useful for designers of electric stations.

(5) The most valuable feature of developed new technology is the absence of natural fossil fuel use, which leads to preserving of environment from pollution and keeps stable climate.

(6) The farther development of considered technology will shape a society of cheap energy consumers, cheap electric stations designers and cheap electricity producers that will spur development of economy of countries and will create prosperous life.

(7) Detailed studies of well-known heating systems, operation principles, kinds of consumed fuels, energy and cost effectiveness and other constructive and operational features it is concluded that developed fossil fuels non-consuming heating, ventilation and domestic hot water providing integrated system is publically issued and discussed first time.

(8) The critical advantage of developed heat supply integrated system is the prevention of surrounding environment from pollution, because it does not use at all natural fossil fuel.

(9) Hot liquid refrigerant preparation proposed system works as refrigeration open loop high efficiency invers device, as instead of useless waste of condenser's produced heat it is used for air heating useful purpose.
(10) Use of a refrigerator as a heating boiler provides all necessary requirements for realization of the idea of creation fossil fuel non-consuming heat generation and supply system.

(11) Analyses prove the higher energy efficiency and cost effectiveness of developed fossil fuel non-consuming heat supply integrated system compared to well-known traditional types of heat generation and supply systems.

(12) Experimental implementation of developed fossil fuel non-consuming integrated heat supply system and its farther studies will spur new system's wide use, will create plentiful of new job places, and will develop economy of the country.

\section{References}

[1] Musatov, B. T. 1936. "Deflectors for Ventilation." Technical Notes, Moscow, CAGI.

[2] Amphous, A., and Kharitonov, V. P. 2001. "Deflectors and Energy Saving's Problems." 3rd Forum-Heat \& Vent, Moscow.

[3] Hanlon, P. C. 2001. Compressor Handbook. The McGraw-Hill Companies.

[4] Sarkar, A., and Behera, D. K. 2012. "Wind Turbine Blade Efficiency and Power Calculation with Electrical Analogy." International Journal of Scientific and Research Publications 2 (2). ISSN 2250-3153.

[5] Giampaolo, T. 2006. Gas Turbine Handbook: Principles and Practices. Fairmont Press.

[6] Melikyan, Z. 2015. "A Novel Technology for Generation of Electricity and Cold by Using Energy Potential of Transmission Line's." Journal of Energy and Power Engineering 9: 852-9. doi: 10.17265/1934-8975/2015. 010.003 .

[7] Rajput, R. K. 2007. Engineering Thermodynamics (3rd ed.). Laxmi Publications.

[8] Moran, M. J., and Shapiro, H. N. 2006. Fundamentals of Engineering Thermodynamics. The Atrium, Southern Gate, Chichester, West Sussex PO19 8SQ, England: John Wiley \& Sons Ltd.

[9] Litvin, L. M. 1963. Technical Thermodynamics. Textbook for Institutions of Higher Education. Gosenergoizdat, Moscow-Leningrad.

[10] Al-Shemmeri, T. 2010. Engineering Thermodynamics. Ventus Publishing ApS.

[11] Cimbala, J. M. 2014. The Ideal Gas Constant. Penn State University. 
[12] "Construction Climatology" Construction Norms of Republic of Armenia II-7.01-2011.

[13] Https://www.fiak.ru/upload/medialibrary/e9e/e9eef8493f 709d26726aa52bf166db32.pdf.

[14] Http://www.sahen.elektra.ru/page.php?id=160.

[15] Https://www.fps-compressors.com/index.php/en/brands-2 /test/115-price-list.

[16] http://www.gaselectricpartnership.com/SwRI\%20WHR\% 20gas\%20electric_2009.pdf.

[17] http://www.energodrive.ru/price-electromotor.asp.

[18] Shan, K. W. 2000. Handbook of Air Conditioning and Refrigeration. New York: McGraw-Hill.

[19] Melikyan, Z. A. 2012. Heating-Cooling of Buildings. Efficiency of Conventional and Renewable Technologies. Germany: LAP Lambert Academic Publishing.

[20] Melikyan, Z. A., and Egnatosyan, S. M. 2015. Residential Buildings: Heating Loads. Encyclopedia of Energy Engineering and Technology (2nd ed.). New York: Taylor and Francis.

[21] John, H. LIV., and John, H. L. V. 2003. A Heat Transfer Textbook. Cambridge, Massachusetts: Phlogiston Press.

[22] Russell, F., Robinson, S., and Wagner, N. 2008. Mass and Heat Transfer-Analysis of Mass Contactors and Heat Exchangers. New York: United States of America by Cambridge University Press.

[23] Baehr, H. D., and Stephan, K. 2011. Heat and Mass Transfer. Heidelberg, Dordrecht, London, New York: Springer.

[24] Mark, S. O. 2013. ASHRAE Handbook-Fundamentals 2013: Mark, S. O., Heather, E. K., Chapter 2 Thermodynamics and Refrigeration Cycles. ASHRAE, Inc.

[25] Whitman, B. 2008. Refrigeration \& Air Conditioning Technology (6th ed.). Cengage Learning.

[26] Http://refrigerationandairconditioning.danfoss.ru/pricelist /\#/.

[27] https://www.termoros.com/buyers/prices/. 